\title{
Preoperative alpha-fetoprotein slope is predictive of hepatocellular carcinoma recurrence after liver transplantation
}

\author{
Kathy Han BSc, George N Tzimas MD, Jeffrey S Barkun MD, Peter Metrakos MD, \\ Jean I Tchervenkov MD, Nir Hilzenrat MD, Phil Wong MD, Marc Deschênes MD
}

\begin{abstract}
K Han, GN Tzimas, JS Barkun, et al. Preoperative alphafetoprotein slope is predictive of hepatocellular carcinoma recurrence after liver transplantation. Can J Gastroenterol 2007;21(1):39-45.
\end{abstract}

BACKGROUND: Liver transplantation (LT) offers a possible cure for patients with hepatocellular carcinoma (HCC) and cirrhosis. However, tumour progression while on the waiting list and tumour recurrence after LT are common. The prognostic significance of various pre- and postoperative variables were investigated in regard to tumour recurrence, with an emphasis on the slope of preoperative serum alpha-fetoprotein (AFP) levels

PATIENTS AND METHODS: Data from 48 patients who had HCC diagnosed preoperatively and underwent LT at the McGill University Health Centre (Montreal, Quebec) were reviewed retrospectively, and possible risk factors for tumour recurrence were examined.

RESULTS: Univariate analysis revealed a positive correlation between the preoperative AFP slope and vascular invasion $(\mathrm{P}=0.045)$, total tumour diameter at explant $(\mathrm{P}=0.040)$, Cancer of the Liver Italian Program score $(\mathrm{P}=0.017)$ and recurrence-free survival $(\mathrm{P}=0.028)$. Of the preoperative variables examined, only the preoperative AFP slope was identified as an independent predictor of tumour recurrence by multivariate analysis. Receiver operating characteristic analysis showed that the best discriminant cut-off value, calculated as the value of the maximized likelihood ratio, was preoperative AFP slope greater than $50 \mu \mathrm{g} / \mathrm{L}$ per month. At this cut-off, sensitivity was $36 \%$, and specificity was $97 \%$. Patients with a preoperative AFP slope greater than $50 \mu \mathrm{g} / \mathrm{L}$ per month had a much worse one-year recurrence-free survival rate than those with a preoperative AFP slope $50 \mu \mathrm{g} / \mathrm{L}$ per month or less (40\% versus $90 \%, \mathrm{P}<0.001$ ).

CONCLUSIONS: These results suggest that the preoperative AFP be examined in future studies of patients receiving LT for HCC.

Key Words: Alpha-fetoprotein slope; Hepatocellular carcinoma; Liver transplantation; Tumour recurrence slope is an important predictor of HCC recurrence after LT and should

\section{La pente alpha-fotoprotéique préopératoire est prédictrice de la récurrence de carcinome hépatocellulaire après une greffe du foie}

\begin{abstract}
HISTORIQUE : La greffe du foie (GF) constitue une cure possible pour les patients atteints d'un carcinome hépatocellulaire $(\mathrm{CHC})$ et d'une cirrhose. Cependant, la progression de la tumeur pendant que le patient est sur la liste d'attente et sa récurrence après la GF sont courantes. On a évalué la signification pronostique de diverses variables préopératoires et postopératoires pour ce qui est de la récurrence de la tumeur, et surtout la pente des taux d'alpha-fœetoprotéines (SFP) sériques préopératoires.

PATIENTS ET MÉTHODOLOGIE : Les données provenant de 48 patients chez qui un $\mathrm{CHC}$ avait été diagnostiqué avant l'opération et qui avaient subi une GF au Centre universitaire de santé McGill ont fait l'objet d'une analyse prospective, et on a examiné les facteurs de risque possibles de récurrence de la tumeur.

RÉSULTATS : L'analyse univariable a révélé une corrélation positive entre la pente AFP préopératoire et l'invasion vasculaire $(\mathrm{P}=0,045)$, le diamètre total de la tumeur à l'explantation $(\mathrm{P}=0,040)$, l'indice du programme italien du cancer hépatique $(\mathrm{P}=0,017)$ et la survie sans récurrence $(\mathrm{P}=0,028)$. Parmi les variables préopératoires examinées, seule la pente AFP préopératoire a été repérée comme un prédicteur indépendant de récurrence de la tumeur par analyse multivariée. L'analyse des caractéristiques opératoires du receveur a révélé que la meilleure valeur seuil discriminatoire, calculée à titre de valeur du ratio de vraisemblance maximisé, était une pente AFP préopératoire supérieure à $50 \mu \mathrm{g} / \mathrm{L}$ par mois. À ce seuil, la sensibilité était de $36 \%$, et la spécificité, de $97 \%$. Les patients dont la pente d'AFP préopératoire était supérieure à $50 \mu \mathrm{g} / \mathrm{L}$ par mois affichaient un taux de survie sans récurrence au bout d'un mois beaucoup moins reluisant que ceux dont la pente AFP préopératoire était de $50 \mu \mathrm{g} / \mathrm{L}$ par mois ou moins ( $40 \%$ par rapport à $90 \%, \mathrm{P}<0,001$ ).

CONCLUSIONS : D'après ces résultats, la pente AFP préopératoire est un important prédicteur de récurrence de $\mathrm{CHC}$ après une GF et devrait être examinée dans les futures études de patients subissant une GF en raison d'un $\mathrm{CHC}$.
\end{abstract}

$\mathrm{H}$ epatocellular carcinoma (HCC) is the fifth most common cancer worldwide (1) and its incidence has increased substantially in North America, Europe and Japan over the past 30 years $(2-4)$. HCC results in approximately 500,000 deaths annually (1). Cirrhosis, mainly caused by hepatitis $\mathrm{B}$ and $\mathrm{C}$ viruses, and alcohol, is the dominant risk factor for HCC (4). Liver transplantation (LT) offers a possible cure for selected patients with HCC and cirrhosis,

because it simultaneously removes both the tumour and the underlying cirrhosis (4).

With the steadily increasing waiting time for LT induced by the relative shortage of donors, an HCC has the opportunity to grow in size. Patients are therefore often offered the possibility of receiving preoperative adjuvant treatments in an attempt to delay progression and decrease the risk of recurrence. However, available treatments, such

Liver Transplant Program, Royal Victoria Hospital, McGill University Health Centre, Montreal, Quebec

Correspondence: Dr Marc Deschênes, Royal Victoria Hospital, 687 Pine Avenue West, R2.11, McGill University Health Centre, Montreal,

Quebec H3A 1A1. Telephone 514-843-1616, fax 514-843-1421, e-mail marc.deschenes@muhc.mcgill.ca

Received for publication June 3, 2005. Accepted April 11, 2006 
as transarterial chemoembolization (TACE), intra-arterial chemotherapy, radiofrequency ablation and percutaneous ethanol injection, have a controversial impact on survival (5). Given the shortage of donors, it is thus important to examine factors that may predict the best results from LT to optimize the allocation of organs and survival rates.

Many studies have shown that the total tumour diameter in the explanted liver correlates with the risk of tumour recurrence (6-8). Because of the prolonged waiting time and the limited accuracy of imaging techniques, it is not unusual that the ultimate total tumour load of the explanted liver is more than had been previously predicted with preoperative imaging. Besides imaging, another readily available preoperative test is the serum alpha-fetoprotein (AFP). AFP is a widely used tumour marker for the detection, surveillance and monitoring of HCC. Although a significant proportion of HCCs secrete elevated levels of AFP, serum AFP levels can remain low (less than $20 \mu \mathrm{g} / \mathrm{L}$ ) in up to $40 \%$ of cirrhotic patients who are not hepatitis B virus carriers $(9,10)$. While some studies suggest that an elevated serum AFP level at the time of diagnosis is associated with poorer prognosis, others have failed to show such a correlation (11). Instead of focusing on single static values of AFP, we investigated the possible prognostic significance of the slope of serial AFP values measured during the waiting time before LT. We thus conducted a retrospective study of 48 patients who had HCC and underwent LT to examine possible risk factors for HCC recurrence, with emphasis on whether a correlation exists between the slope of pre-LT AFP measurements and various pathological and clinical outcomes.

\section{PATIENTS AND METHODS}

All patients who received LTs and were diagnosed with HCC at the McGill University Health Centre (Montreal, Quebec) between November 1991 and April 2003 were identified through the McGill University Transplantation Database. The diagnosis of HCC was confirmed in all cases by the histological findings of the explanted liver. Of the 76 patients identified, 13 were excluded because only a single preoperative AFP value had been obtained and, thus, the AFP slope could not be calculated. Two of the 13 patients developed recurrence. Patients whose tumours had not been identified preoperatively were defined as incidental $(n=15)$, and were considered separately because the prognosis of the group is known to be better $(6,12)$. The following data were collected for the remaining 48 nonincidental cases: age, sex, ethnic background, etiology of liver disease, Model End-Stage Liver Disease (MELD) score, pretransplantation treatment with TACE, percutaneous ethanol injection or intra-arterial chemotherapy, preoperative AFP values, results of the last imaging study before LT (number of lesions, total tumour diameter and portal vein thrombosis), the explant histology (number of lesions, total tumour diameter, tumour differentiation and vascular invasion), and the Cancer of the Liver Italian Program (CLIP) score (13). The MELD score reported in the present study reflects the liver disease itself (international normalized ratio, bilirubin and creatinine), without correction for HCC (14). Mortality data were assessed as of July 3, 2003. Subgroup analyses were also performed on patients according to whether the tumours had met the Milan criteria ( $n=29)(15)$.

Between 1997 and 2002, patients with HCCs exceeding the Milan criteria (ie, single tumour greater than $5 \mathrm{~cm}$, or more than three small tumours) had been enrolled in a protocol where they had received TACE with carboplatin, iodized oil and gelatin pellets for three cycles (four to six weeks apart). Those on the waiting list for more than two months after three treatments received a fourth TACE treatment. Also between 1997 and 2002, patients on the LT wait list with a small single tumour received percutaneous ethanol injections.

\section{Calculation of the preoperative AFP slope}

Preoperative AFP levels were measured using the Centaur Automated Chemiluminescence System (Bayer Diagnostics, USA) for each patient, and individual graphs were plotted with AFP levels on the $\mathrm{y}$ axis and time on the $\mathrm{x}$ axis. The AFP slope was calculated using the 'SLOPE' function of Microsoft Excel 2002 (Microsoft Co, USA). All available AFP levels were included in the model, with the exception of four patients in whom the AFP slopes were biphasic (ie, increasing slope, then dramatically decreasing slope or vice versa). For those four patients, the AFP slope pattern closest to the time of transplantation was used in the subsequent analysis. For example, if a patient initially had a decreasing AFP pattern, but then an increasing AFP pattern closer to the time of transplantation, the positive AFP slope was used. While on the waiting list, the patients' AFP levels had been scheduled every three months. However, depending on the patients' compliance and time on the waiting list, the number of data points and interval between AFP measurements were not necessarily the same for all patients. A median of four data points (range two to 11) were used to calculate the AFP slopes. The median interval between individual AFP measurements was 42 days (interquartile range 90 days).

\section{Statistical analysis}

The relationship between the preoperative AFP slope and various postoperative variables and the type of preoperative treatment was examined using the Mann-Whitney U or Kruskal-Wallis test. Univariate and multivariate Cox regression analyses were performed to identify risk factors for tumour recurrence and survival using StatsDirect, version 2.3.1 (StatsDirect Ltd, United Kingdom). The receiver operating characteristic (ROC) curve was constructed using Analyse-it software (Analyse-It Software, Ltd, United Kingdom). The optimal cut-off was determined by the preoperative AFP slope that yielded the greatest maximum likelihood ratio. Survival curves were generated using the Kaplan-Meier method and differences between curves were tested using the log-rank test. $\mathrm{P}<0.05$ was considered statistically significant.

\section{Patient and tumour characteristics}

The characteristics of all 48 patients and the subgroup of patients $(n=29)$ who met the Milan criteria are summarized in Table 1 . The median waiting time for LT was 30 days (range one to 1167 days). For many years, in Quebec, patients with HCC have been given waiting list priority for LT, even before implementation of the MELD score. The median MELD score was 24.4 (range 20 to 45). As of July 3, 2003, the median follow-up time was 3.7 years (range 0.3 to 11.6 years). Overall, a total of 17 recipients $(35.4 \%)$ had died, whereas 11 recipients $(22.9 \%)$ had developed HCC recurrence. Of the 29 patients who had met the Milan criteria, nine (31.0\%) had died and four $(13.8 \%)$ had developed HCC recurrence. The majority of the HCCs were moderately differentiated. Lymph nodes were identified in 24 explanted livers, and all of them were found to be lymph node negative through examination or resection at time of transplant. 
TABLE 1

Characteristics of patients and tumours

\begin{tabular}{|c|c|c|}
\hline Characteristics & $\begin{array}{l}\text { All nonincidental } \\
\text { cases }(n=48) \\
n(\%)\end{array}$ & $\begin{array}{c}\text { Nonincidental } \\
\text { cases that met the } \\
\text { Milan criteria }(n=29) \\
n(\%)\end{array}$ \\
\hline Age, years (mean $\pm S D)$ & $61 \pm 7$ & $60 \pm 7$ \\
\hline Sex, male/female & $42 / 6$ & $23 / 6$ \\
\hline Asian/non-Asian & $5 / 43$ & $4 / 25$ \\
\hline \multicolumn{3}{|l|}{ Etiology of liver disease } \\
\hline Hepatitis $B$ virus & $12(25.0)$ & $6(20.7)$ \\
\hline Hepatitis $C$ virus & $22(45.8)$ & $14(48.3)$ \\
\hline Other & $14(29.2)$ & $9(31.0)$ \\
\hline \multicolumn{3}{|l|}{ Preoperative treatment for $\mathrm{HCC}^{*}$} \\
\hline Transarterial chemoembolization ${ }^{\dagger}$ & $14(29.2)$ & $5(17.2)$ \\
\hline Percutaneous ethanol injection & $6(12.5)$ & $3(10.3)$ \\
\hline Intra-arterial chemotherapy & $6(12.5)$ & $4(13.8)$ \\
\hline None & $25(52)$ & $19(65.5)$ \\
\hline \multicolumn{3}{|l|}{$\begin{array}{l}\text { Number of lesions detected } \\
\text { by imaging }\end{array}$} \\
\hline$n=1$ & $30(63)$ & $23(79.3)$ \\
\hline$n>1$ & $18(38)$ & $6(20.7)$ \\
\hline \multicolumn{3}{|l|}{$\begin{array}{l}\text { Total tumour diameter detected } \\
\text { by imaging }\end{array}$} \\
\hline$\leq 7 \mathrm{~cm}$ & $37(77.1)$ & $28(96.7)$ \\
\hline$>7 \mathrm{~cm}$ & $11(22.9)$ & $1(3.4)$ \\
\hline Portal vein thrombosis & $4(8)$ & $3(10.3)$ \\
\hline \multicolumn{3}{|l|}{ Number of lesions at explant } \\
\hline$n=1$ & $17(35.4)$ & $13(44.8)$ \\
\hline$n>1$ & $31(64.6)$ & $16(55.2)$ \\
\hline \multicolumn{3}{|l|}{ Total tumour diameter at explant } \\
\hline$\leq 7 \mathrm{~cm}$ & $35(72.9)$ & $25(86.2)$ \\
\hline$>7 \mathrm{~cm}$ & $13(27.1)$ & $4(13.8)$ \\
\hline Vascular invasion & $15(31.3)$ & $9(31.0)$ \\
\hline \multicolumn{3}{|l|}{ Tumour differentiation } \\
\hline Well differentiated & $12(25.0)$ & $8(27.6)$ \\
\hline Moderately differentiated & $31(64.6)$ & $19(65.5)$ \\
\hline Poorly differentiated & $5(10.4)$ & $2(6.9)$ \\
\hline
\end{tabular}

Except for the section on 'Preoperative treatment for hepatocellular carcinoma (HCC)', all other sections add up to $100 \%$. *Some patients received more than one type of therapy; ${ }^{\dagger}$ Fourteen patients whose tumours exceeded the Milan criteria were initially treated with transarterial chemoembolization while on the waiting list between 1997 and 2002. Following treatment with transarterial chemoembolization, five patients'tumours met the Milan criteria (according to the last preoperative imaging study)

Findings at the last imaging study before LT and tumour characteristics at explant are summarized in Table 1. The last preoperative imaging study was performed a median of 39 days (range one to 183 days) before LT. In other series (16-18), radiological findings were not able to accurately predict the number of lesions, nor the total tumour burden ultimately found at explant.

Preoperative AFP levels and slopes

The timing of preoperative AFP measurements and actual levels, as well as the number of patients with positive, zero and negative slopes are presented in Table 2. Three patients' AFP levels remained normal (less than $10 \mu \mathrm{g} / \mathrm{L}$ ), yet all three patients developed HCC recurrence. Only one of them met the Milan criteria. Two of these patients had a positive slope whereas the other had a slightly negative slope.
TABLE 2

Preoperative alpha-fetoprotein (AFP) levels and slopes

\begin{tabular}{|c|c|c|}
\hline $\begin{array}{l}\text { AFP levels and } \\
\text { slopes }\end{array}$ & $\begin{array}{l}\text { Nonincidental } \\
\text { cases }(n=48)\end{array}$ & $\begin{array}{c}\text { Nonincidental cases } \\
\text { that met the Milan } \\
\text { criteria }(n=29)\end{array}$ \\
\hline \multicolumn{3}{|l|}{ Median (range) } \\
\hline First AFP level ( $\mu \mathrm{g} / \mathrm{L})$ & $18.4(2.01-12247)$ & $16.4(0-12247)$ \\
\hline Last AFP level ( $\mu \mathrm{g} / \mathrm{L})$ & $38.0(2.5-7600)$ & $18.0(2.5-7600)$ \\
\hline $\begin{array}{l}\text { Timing of the first AFP level } \\
\text { (days before LT) }\end{array}$ & $208(9-1274)$ & $220(9-1274)$ \\
\hline $\begin{array}{l}\text { Timing of the last AFP level } \\
\text { (days before LT) }\end{array}$ & $32(1-254)$ & $30(1-254)$ \\
\hline \multicolumn{3}{|l|}{ Patients, $\mathrm{n}$} \\
\hline AFP slope $>100 \mu g / L$ per month & 3 & 2 \\
\hline AFP slope $>50 \mu \mathrm{g} / \mathrm{L}$ per month & 5 & 3 \\
\hline AFP slope $>0 \mu \mathrm{g} / \mathrm{L}$ per month & 25 & 17 \\
\hline AFP slope $\leq 0 \mu \mathrm{g} / \mathrm{L}$ per month & 23 & 12 \\
\hline
\end{tabular}

TABLE 3

Univariate analysis of variables potentially associated with the preoperative alpha-fetoprotein slope

\begin{tabular}{lc}
\hline Variables & $\mathbf{P}$ \\
\hline Meets Milan criteria & 0.660 \\
Preoperative treatment & 0.542 \\
Tumour differentiation* & 0.171 \\
Number of lesions* & 0.743 \\
Vascular invasion* & 0.045 \\
Total tumour diameter $(\leq 7 \mathrm{~cm} \text { versus }>7 \mathrm{~cm})^{*}$ & 0.040 \\
Cancer of the Liver Italian Program score $(0-2$ versus 3-5) & 0.017 \\
Tumour recurrence & 0.028 \\
\hline
\end{tabular}

$P<0.05$ is considered to be significant. ${ }^{*}$ Based on the pathology report

The relationship between the preoperative AFP slope and various postoperative variables, and the type of pretransplantation treatment was examined by univariate analysis (Table 3 ). The preoperative AFP slope was found to be associated with a total tumour diameter at explant greater than $7 \mathrm{~cm}$, vascular invasion, high CLIP score and HCC recurrence after LT. In contrast, there was no association between the last preoperative AFP level and tumour recurrence. The difference between the median of the last preoperative AFP level in patients with a recurrence $(63 \mu \mathrm{g} / \mathrm{L})$ compared with those without a recurrence $(18 \mu \mathrm{g} / \mathrm{L})$ was not statistically significant $(\mathrm{P}=0.54)$.

Cox regression analysis

Univariate Cox regression analysis was performed on possible factors associated with HCC recurrence, including the radiological and histological variables listed in Table 1, as well as the last preoperative AFP level and the slope of preoperative AFP levels listed in Table 2. Of these 48 patients, total tumour diameter greater than $7 \mathrm{~cm}$ (based on the pathology reports), vascular invasion and the preoperative AFP slope were the only significant predictors of HCC recurrence (Table 4). Stratification of the AFP slope (greater than $0 \mu \mathrm{g} / \mathrm{L}$ per month, greater than $50 \mu \mathrm{g} / \mathrm{L}$ per month and greater than $100 \mu \mathrm{g} / \mathrm{L}$ per month) revealed a positive correlation between the magnitude of the slope and the risk of HCC recurrence in univariate analysis (Table 4). Factors found 
TABLE 4

Univariate analysis of risk factors for tumour recurrence after liver transplantation for hepatocellular carcinoma (HCC)

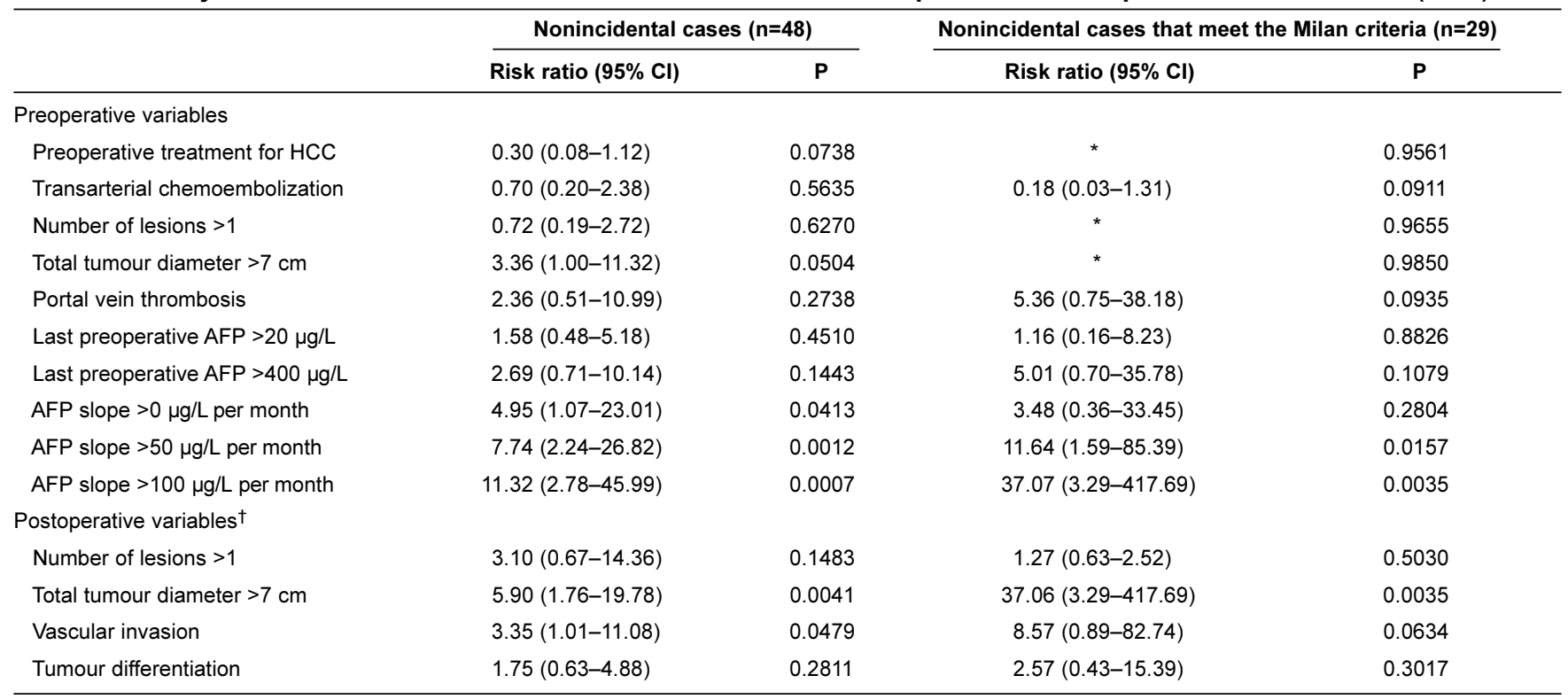

$P<0.05$ is considered to be significant. ${ }^{*}$ The confidence interval is too wide and insignificant. ${ }^{\dagger}$ Based on the pathology report. AFP Alpha-fetoprotein

TABLE 5

Multivariate analysis of risk factors for tumour recurrence after liver transplantation for hepatocellular carcinoma

\begin{tabular}{|c|c|c|c|c|}
\hline & \multicolumn{2}{|c|}{ Nonincidental cases $(n=48)$} & \multicolumn{2}{|c|}{ Nonincidental cases that meet the Milan criteria $(n=29)$} \\
\hline & Risk ratio $(95 \% \mathrm{Cl})$ & $\mathbf{P}$ & Risk ratio $(95 \% \mathrm{Cl})$ & $\mathbf{P}$ \\
\hline Vascular invasion* & $2.93(0.84-10.26)$ & 0.0932 & - & - \\
\hline AFP slope $>0 \mu g / L$ per month & $5.96(1.20-29.71)$ & 0.0294 & - & - \\
\hline Vascular invasion* & $2.06(0.56-7.58)$ & 0.278 & - & - \\
\hline Total tumour diameter $>7 \mathrm{~cm}^{*}$ & $5.58(1.53-20.43)$ & 0.0094 & $\dagger$ & 0.9770 \\
\hline Vascular invasion* & $1.69(0.39-7.26)$ & 0.4800 & - & - \\
\hline Total tumour diameter $>7 \mathrm{~cm}^{*}$ & $5.12(1.45-18.11)$ & 0.0113 & $1(1-1)$ & $<0.0001$ \\
\hline AFP slope $>100 \mu g / L$ per month & $6.71(1.22-36.92)$ & 0.0286 & $37.06(3.29-17.69)$ & 0.0035 \\
\hline
\end{tabular}

$P<0.05$ is considered to be significant. ${ }^{*}$ Postoperative variables based on tumour characteristics at explant; ${ }^{\dagger}$ The confidence interval is too wide and insignificant. AFP Alpha-fetoprotein

to be significant by univariate analysis were subsequently included as covariates in multivariate analysis using Cox's proportional hazard regression (Table 5). Cox's models were fit separately for AFP slopes greater than $0 \mu \mathrm{g} / \mathrm{L}$ per month, greater than $50 \mu \mathrm{g} / \mathrm{L}$ per month and greater than $100 \mu \mathrm{g} / \mathrm{L}$ per month. When AFP slope greater than $0 \mu \mathrm{g} / \mathrm{L}$ per month was used, vascular invasion and total tumour diameter greater than $7 \mathrm{~cm}$ (based on the pathology reports) were introduced as covariates, only AFP slope greater than $0 \mu \mathrm{g} / \mathrm{L}$ per month and total tumour diameter greater than $7 \mathrm{~cm}$ were independent predictors of HCC recurrence. When AFP slope greater than $50 \mu \mathrm{g} / \mathrm{L}$ per month was included instead of AFP slope greater than $0 \mu \mathrm{g} / \mathrm{L}$ per month, AFP slope greater than $50 \mu \mathrm{g} / \mathrm{L}$ per month and total tumour diameter greater than $7 \mathrm{~cm}$ were found to be independently associated with greater recurrence rates. Finally, inclusion of AFP slope greater than $100 \mu \mathrm{g} / \mathrm{L}$ per month as a covariate in place of AFP slope greater than $0 \mu \mathrm{g} / \mathrm{L}$ per month, resulted in AFP slope greater than $100 \mu \mathrm{g} / \mathrm{L}$ per month and total tumour diameter greater than $7 \mathrm{~cm}$ as independent factors influencing the risk of HCC recurrence (Table 5).
ROC analysis showed that the best discriminant cut-off value, calculated as the value of the maximized likelihood ratio, was AFP slope greater than $50 \mu \mathrm{g} / \mathrm{L}$ per month (Figure 1A). At this cut-off, sensitivity was $36 \%$, specificity was $97 \%$, positive predictive value was $80 \%$, and negative predictive value was $84 \%$. Figure $1 \mathrm{~B}$ shows the recurrence-free survival of all LT recipients, and survival according to the value of the preoperative AFP slope (greater than $50 \mu \mathrm{g} / \mathrm{L}$ per month, or $50 \mu \mathrm{g} / \mathrm{L}$ per month or less). The one-year recurrence-free survival rate of patients with preoperative AFP slope greater than $50 \mu \mathrm{g} / \mathrm{L}$ per month was less than one-half in patients with AFP slope $50 \mu \mathrm{g} / \mathrm{L}$ per month or less (40\% versus $90 \%, \mathrm{P}<0.001)$.

Subgroup analyses

A separate analysis was performed on patients whose tumours preoperatively met the Milan criteria $(n=29)$. Among this subgroup of patients, on univariate analysis, only total tumour diameter greater than $7 \mathrm{~cm}$ (based on the pathology reports), AFP slope greater than $50 \mu \mathrm{g} / \mathrm{L}$ per month and AFP slope greater than $100 \mu \mathrm{g} / \mathrm{L}$ per month were found to be statistically 


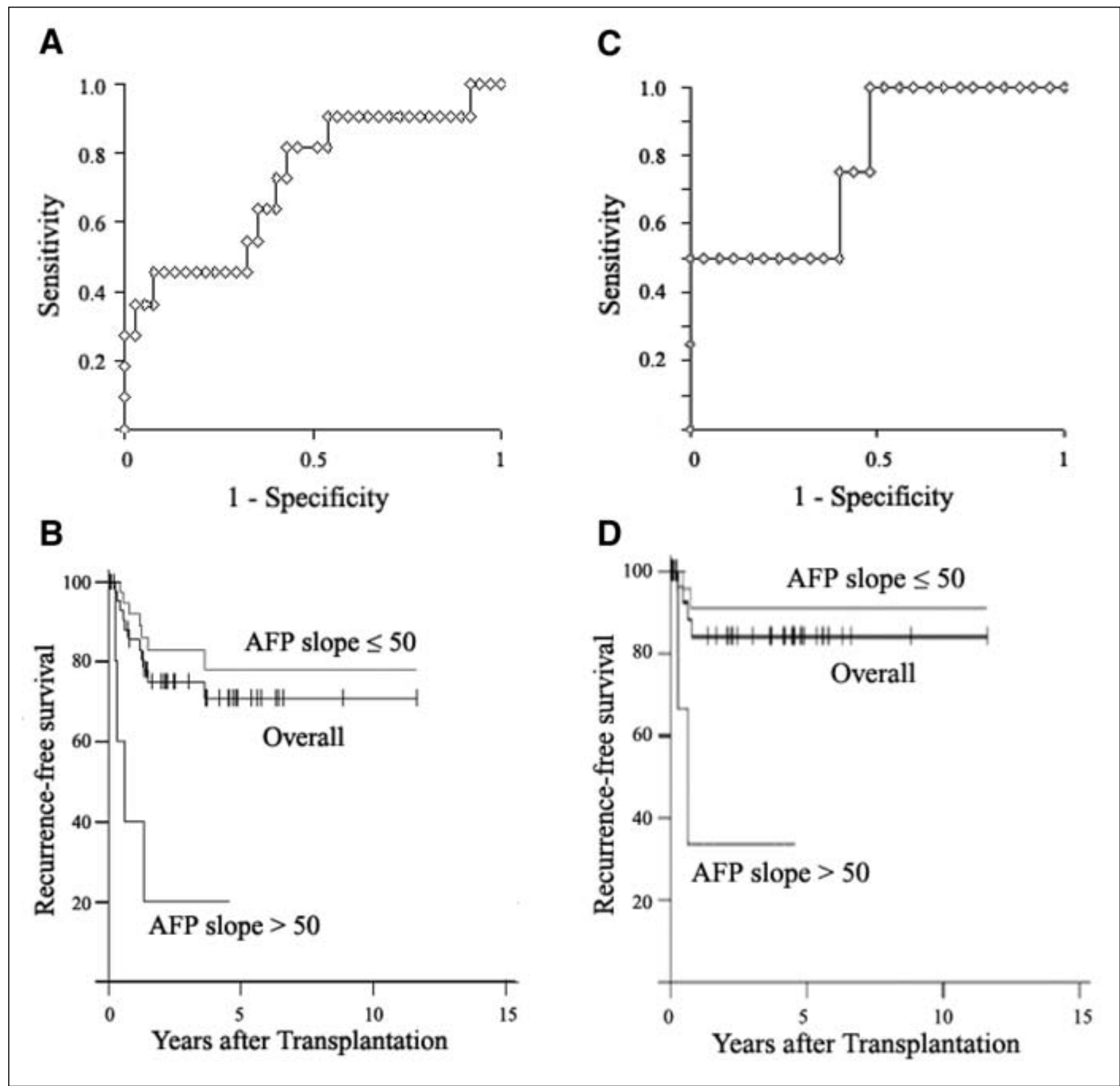

Figure 1) A Receiver operating characteristic analysis of the ability of the preoperative alpha-fetoprotein (AFP) slope to predict hepatocellular carcinoma (HCC) recurrence after liver transplantation (LT) in 48 patients. B Kaplan-Meier recurrence-free survival (middle curve) of 48 patients after LT for HCC and recurrence-free survival according to the preoperative AFP slope. Transplant recipients with a preoperative AFP slope greater than $50 \mu \mathrm{g} / \mathrm{L}$ per month had a worse outcome than those with a preoperative AFP slope less than or equal to $50 \mu \mathrm{g} / \mathrm{L}$ per month $(\mathrm{P}<0.001)$. C Receiver operating characteristic analysis of the ability of the preoperative AFP slope to predict HCC recurrence after LT in the 29 patients who met the Milan criteria. D Kaplan-Meier recurrence-free survival curve of the 29 patients who met the Milan criteria. Those with a preoperative AFP slope greater than $50 \mu \mathrm{g} / \mathrm{L}$ per month had a worse outcome than those with a preoperative AFP slope less than or equal to $50 \mu \mathrm{g} / \mathrm{L}$ per month $(P=0.002)$

significant as predictors for HCC recurrence (Table 5). When multivariate Cox regression analysis was carried out on total tumour diameter greater than $7 \mathrm{~cm}$ (based on the pathology reports) and AFP slope greater than $100 \mu \mathrm{g} / \mathrm{L}$ per month, both were independent predictors of HCC recurrence. The optimal cut-off shown on the ROC analysis was also AFP slope greater than $50 \mu \mathrm{g} / \mathrm{L}$ per month (Figure $1 \mathrm{C}$ ). At this cut-off, sensitivity was $50 \%$, specificity was $96 \%$, positive predictive value was $67 \%$, and negative predictive value was $92 \%$. The one-year recurrence-free survival rate of patients with preoperative AFP slope greater than $50 \mu \mathrm{g} / \mathrm{L}$ per month was almost one-third in patients with AFP slope $50 \mu \mathrm{g} / \mathrm{L}$ per month or less (33\% versus $91 \%, \mathrm{P}=0.002$ ) (Figure 1D).

Incidental cases (data not shown)

The data for incidental cases $(n=15)$ were not shown because realistically, it would not be feasible to monitor the preoperative AFP slope for patients who were not diagnosed with HCC 
before LT. In addition, this group of patients are known to have a better prognosis $(6,12)$. However, to be thorough, the incidental cases are described below.

Only three patients (20\%) developed tumour recurrence, and all three had a positive AFP slope. Five patients' preoperative AFP levels remained normal (less than $10 \mu \mathrm{g} / \mathrm{L}$ ). All of the above regression results were applicable even when incidental cases were included in the analyses. On univariate regression analysis, total tumour diameter greater than $7 \mathrm{~cm}$ (based on the pathology reports), vascular invasion and the preoperative AFP slope were significant predictors for HCC recurrence when considering all patients $(n=63)$. Cox's models were fit separately for AFP slopes greater than $0 \mu \mathrm{g} / \mathrm{L}$ per month, greater than $50 \mu \mathrm{g} / \mathrm{L}$ per month and greater than $100 \mu \mathrm{g} / \mathrm{L}$ per month. When multivariate Cox regression analysis was carried out on AFP slope greater than $0 \mu \mathrm{g} / \mathrm{L}$ per month, vascular invasion and total tumour diameter greater than $7 \mathrm{~cm}$, were independent predictors of HCC recurrence. When AFP slope greater than $50 \mu \mathrm{g} / \mathrm{L}$ per month was included instead of AFP slope greater than $0 \mu \mathrm{g} / \mathrm{L}$ per month, only AFP slope greater than $50 \mu \mathrm{g} / \mathrm{L}$ per month and total tumour diameter greater than $7 \mathrm{~cm}$ were independently associated with greater recurrence rates. Finally, inclusion of AFP slope greater than $100 \mu \mathrm{g} / \mathrm{L}$ per month as a covariate in place of AFP slope greater than $0 \mu \mathrm{g} / \mathrm{L}$ per month, resulted in only total tumour diameter greater than $7 \mathrm{~cm}$ as an independent factor influencing the risk of HCC recurrence. The optimal cut-off on ROC analysis of all cases was also AFP slope greater than $50 \mu \mathrm{g} / \mathrm{L}$ per month. At this cut-off, sensitivity was $43 \%$, specificity was $96 \%$, positive predictive value was $75 \%$, and negative predictive value was $87 \%$. The one-year recurrence-free survival rate of patients with preoperative AFP slope greater than $50 \mu \mathrm{g} / \mathrm{L}$ per month was nearly one-half of that in patients with AFP slope less than or equal to $50 \mu g / L$ per month (45\% versus $94 \%, \mathrm{P}<0.001$ ).

\section{DISCUSSION}

We evaluated the prognostic value of the preoperative serum AFP slope compared with other preoperative variables often recorded in the assessment of patients with HCC undergoing LT. Although imaging techniques have improved over the period of the present study (12 years), when we examined patients who underwent LT after 1996 separately, the radiological variables were still not found to be good predictors of HCC recurrence. In fact, the only preoperative variable predictive of HCC recurrence was the preoperative AFP slope. Our finding that the preoperative AFP slope was a prognostic factor for recurrence was further validated by the direct relationship between the preoperative AFP slope and vascular invasion, total tumour diameter at explant and CLIP score.

Previous studies have examined the prognostic significance of AFP levels, but with conflicting results. When AFP level was analyzed at a single preoperative time point as a continuous variable, a positive correlation with survival time was noted in two studies $(19,20)$, but not observed in two others $(21,22)$. However, when AFP level was tested as a categorical variable, the problem of cut-off choice emerged. Whereas Yao et al (23) found AFP levels greater than $1000 \mu g / L$ to be a significant predictor for reduced survival in univariate analysis, Nomura et al (9) found that the relationship holds for only those with tumours less than $5 \mathrm{~cm}$. For tumours greater than $5 \mathrm{~cm}$, but occupying less than $50 \%$ of the liver, prognostic difference was observed only between those with AFP levels less than or equal to $20 \mu \mathrm{g} / \mathrm{L}$ and those with AFP levels greater than $1000 \mu \mathrm{g} / \mathrm{L}$. Shorter survival was also associated with AFP levels greater than $8.5 \mu \mathrm{g} / \mathrm{L}(24), 20 \mu \mathrm{g} / \mathrm{L}(25)$ and $400 \mu \mathrm{g} / \mathrm{L}$ (13), and while Figueras et al (26) and Shetty et al (27) found AFP levels greater than $300 \mu \mathrm{g} / \mathrm{L}$ to be associated with recurrence, Mazzaferro et al (15) did not observe such correlation. The innovative finding in the present study is that, although the absolute preoperative value of AFP is not a predictor, the slope of the preoperative AFP levels is a very strong independent predictor of HCC recurrence.

The present study has a few shortcomings. The retrospective nature of the current study is a weakness, because it may be subjected to bias or confounding variables. In addition, while a median waiting time of 30 days for the entire cohort may appear short, patients with HCC have traditionally been given waiting list priority for LT in Quebec. The median waiting time is prolonged to 136 days for patients who underwent LT after 2000, reflecting the recent shortage of organs. However, our short wait time may become more relevant as Canada moves toward using a MELD-like system for prioritizing organ allocation.

The three-year recurrence-free survival rate of patients with nonincidental tumours is $75 \%$. While this may seem low, our cohort contains some patients whose tumours did not meet the Milan criteria. In fact, in Figure 1D, the incidence of nonincidental cases is higher than the $60 \%$ recorded by the International Tumour Registry (6). Moreover, the five-year recurrence-free survival rate of those who met the Milan criteria is $85 \%$, which is comparable with that of other studies $(15,28)$. Our patient population is not homogenous because of the use of pre-LT treatment between 1997 and 2002. Over that period, we had been carrying out a study to determine the efficacy of TACE in patients with tumours exceeding the Milan criteria (29). Subgroup analyses, however, show that whether we analyzed tumours outside of the Milan criteria, or those tumours that met the Milan criteria, the preoperative AFP slope is still strongly predictive of tumour recurrence. The preoperative AFP slope is also an independent predictor of HCC recurrence both for patients who did and did not receive preoperative therapy. Although preoperative therapy may be a confounder in the present study (as it may affect the AFP level), this is actually desirable. For patients who respond to preoperative therapy, decreasing AFP slope may be a better predictor of HCC recurrence than treatment response itself.

While vascular invasion and total tumour diameter at explant (both postoperative variables) were included as covariates in multivariate analysis, it is not currently possible to accurately determine these preoperatively, and they are thus not applicable as preoperative selective criteria. In our current study, the only preoperative variable that is predictive of HCC recurrence is the preoperative AFP slope. The optimal AFP slope cut-off was determined based on the value of the maximized likelihood ratio. Although our sensitivity is not high, the specificity and negative predictive values are high. Ideally, the optimal AFP slope cut-off would have a high specificity, so as to not deny patients the right to an LT, should their risk of HCC recurrence be low. Future larger studies are needed to confirm the optimal AFP slope cut-off for predicting HCC recurrence.

\section{CONCLUSION}

As the incidence of HCC, the demand and waiting time for LT continue to increase, it is important to identify prognostic 
factors for postoperative HCC recurrence to allocate organs efficiently. Despite technological advancement, the accuracy of preoperative imaging studies has remained limited. The present study shows that the preoperative AFP slope, which is easily obtained clinically, can be a useful preoperative predictor of tumour recurrence following LT. This predictor variable should be examined in future studies of outcome following LT for HCC.

\section{REFERENCES}

1. El-Serag HB. Hepatocellular carcinoma: An epidemiologic view. J Clin Gastroenterol 2002;35:S72-8.

2. El-Serag HB, Mason AC. Rising incidence of hepatocellular carcinoma in the United States. N Engl J Med 1999;340:745-50.

3. elSaadany S, Tepper M, Mao Y, Semenciw R, Giulivi A. An epidemiologic study of hepatocellular carcinoma in Canada. Can J Public Health 2002;93:443-6.

4. Bruix J, Sherman M, Llovet JM, et al; EASL Panel of Experts on HCC. Clinical management of hepatocellular carcinoma. Conclusions of the Barcelona-2000 EASL conference. European Association for the Study of the Liver. J Hepatol 2001;35:421-30.

5. Bruix J, Llovet JM. Prognostic prediction and treatment strategy in hepatocellular carcinoma. Hepatology 2002;35:519-24.

6. Molmenti EP, Klintmalm GB. Liver transplantation in association with hepatocellular carcinoma: An update of the International Tumor Registry. Liver Transpl 2002;8:736-48.

7. Schlitt HJ, Neipp M, Weimann A, et al. Recurrence patterns of hepatocellular and fibrolamellar carcinoma after liver transplantation. J Clin Oncol 1999;17:324-31.

8. Marsh JW, Dvorchik I, Bonham CA, Iwatsuki S. Is the pathologic TNM staging system for patients with hepatoma predictive of outcome? Cancer 2000;88:538-43.

9. Nomura F, Ohnishi K, Tanabe Y. Clinical features and prognosis of hepatocellular carcinoma with reference to serum alpha-fetoprotein levels. Analysis of 606 patients. Cancer 1989;64:1700-7.

10. Daniele B, Bencivenga A, Megna AS, Tinessa V. Alpha-fetoprotein and ultrasonography screening for hepatocellular carcinoma. Gastroenterology 2004;127:S108-12.

11. Tangkijvanich P, Anukulkarnkusol N, Suwangool P, et al. Clinical characteristics and prognosis of hepatocellular carcinoma: Analysis based on serum alpha-fetoprotein levels. J Clin Gastroenterol 2000;31:302-8.

12. Choi SH, Lee HH, Lee DS, et al. Clinicopathological features of incidental hepatocellular carcinoma in liver transplantation. Transplant Proc 2004;36:2293-4.

13. The Cancer of the Liver Italian Program (CLIP) investigators. A new prognostic system for hepatocellular carcinoma: A retrospective study of 435 patients: The Cancer of the Liver Italian Program (CLIP) investigators. Hepatology 1998;28:751-5.

14. Kamath PS, Wiesner RH, Malinchoc M, et al. A model to predict survival in patients with end-stage liver disease. Hepatology 2001;33:464-70.

15. Mazzaferro V, Regalia E, Doci R, et al. Liver transplantation for the treatment of small hepatocellular carcinomas in patients with cirrhosis. N Engl J Med 1996;334:693-9.
FUNDING: Kathy Han is supported by the Canadian Institutes of Health Research (CIHR) Health Professional Student Research Award.

Some of these data were presented at the American Transplant Congress, Boston, Massachusetts, May 15-19, 2004.

16. Mion F, Grozel L, Boillot O, Paliard P, Berger F. Adult cirrhotic liver explants: Precancerous lesions and undetected small hepatocellular carcinomas. Gastroenterology 1996;111:1587-92.

17. Llovet JM, Bruix J, Fuster J, et al. Liver transplantation for small hepatocellular carcinoma: The tumor-node-metastasis classification does not have prognostic power. Hepatology 1998;27:1572-7.

18. Sotiropoulos GC, Malago M, Molmenti E, et al. Liver transplantation for hepatocellular carcinoma in cirrhosis: Is clinical tumor classification before transplantation realistic? Transplantation 2005;79:483-7.

19. Nomura F, Ohnishi K, Honda M, Satomura Y, Nakai T, Okuda K. Clinical features of hepatocellular carcinoma in the elderly: A study of 91 patients older than 70 years. Br J Cancer 1994;70:690-3

20. Yamashita Y, Takahashi M, Koga Y, et al. Prognostic factors in the treatment of hepatocellular carcinoma with transcatheter arterial embolization and arterial infusion. Cancer 1991;67:385-91.

21. Chlebowski RT, Tong M, Weissman J, et al. Hepatocellular carcinoma. Diagnostic and prognostic features in North American patients. Cancer 1984;53:2701-6.

22. Attali P, Prod'Homme S, Pelletier G, et al. Prognostic factors in patients with hepatocellular carcinoma. Attempts for the selection of patients with prolonged survival. Cancer 1987;59:2108-11.

23. Yao FY, Ferrell L, Bass NM, et al. Liver transplantation for hepatocellular carcinoma: Expansion of the tumor size limits does not adversely impact survival. Hepatology 2001;33:1394-403.

24. Stuart KE, Anand AJ, Jenkins RL. Hepatocellular carcinoma in the United States. Prognostic features, treatment outcome, and survival. Cancer 1996;77:2217-2222.

25. De Carlis L, Giacomoni A, Pirotta V, et al. Surgical treatment of hepatocellular cancer in the era of hepatic transplantation. J Am Coll Surg 2003;196:887-97.

26. Figueras J, Ibanez L, Ramos E, et al. Selection criteria for liver transplantation in early-stage hepatocellular carcinoma with cirrhosis: Results of a multicenter study. Liver Transpl 2001;7:877-83.

27. Shetty K, Timmins K, Brensinger C, et al. Liver transplantation for hepatocellular carcinoma validation of present selection criteria in predicting outcome. Liver Transpl 2004;10:911-8.

28. Sutcliffe R, Maguire D, Portmann B, Rela M, Heaton N. Selection of patients with hepatocellular carcinoma for liver transplantation. Br J Surg 2006;93:11-8

29. Tzimas G, Metrakos P, Wexler M, et al. Expanded indications for liver transplantation of hepatomas, using intrahepatic chemoembolization with carboplatin: Results of a prospective study. Hepatology 2002;36:393A. (Abst) 


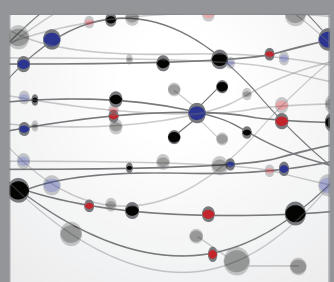

The Scientific World Journal
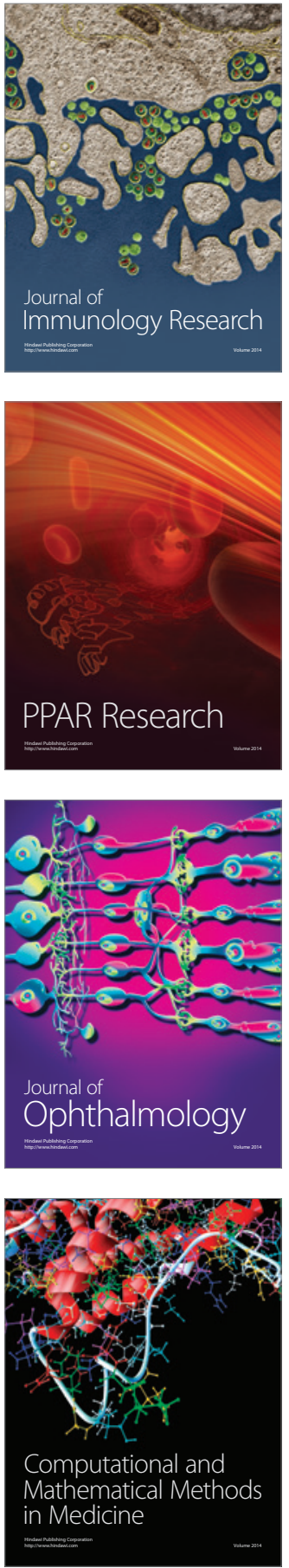

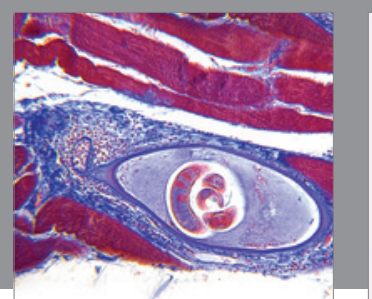

Gastroenterology Research and Practice

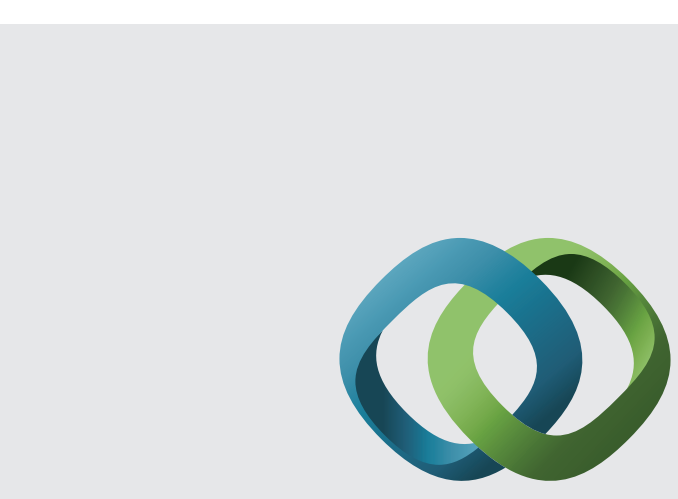

\section{Hindawi}

Submit your manuscripts at

http://www.hindawi.com

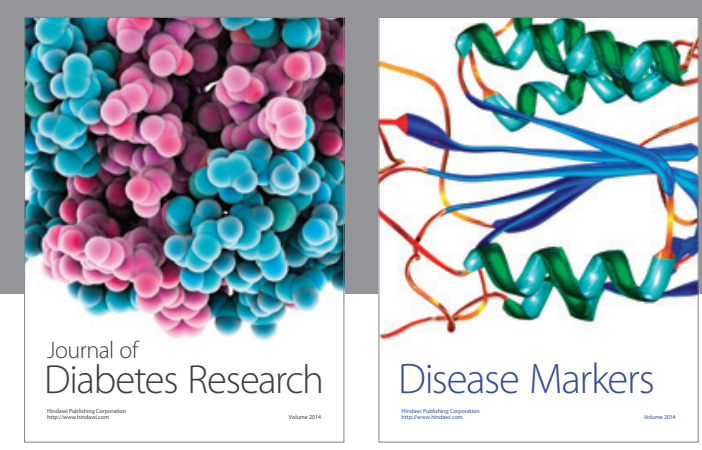

Disease Markers
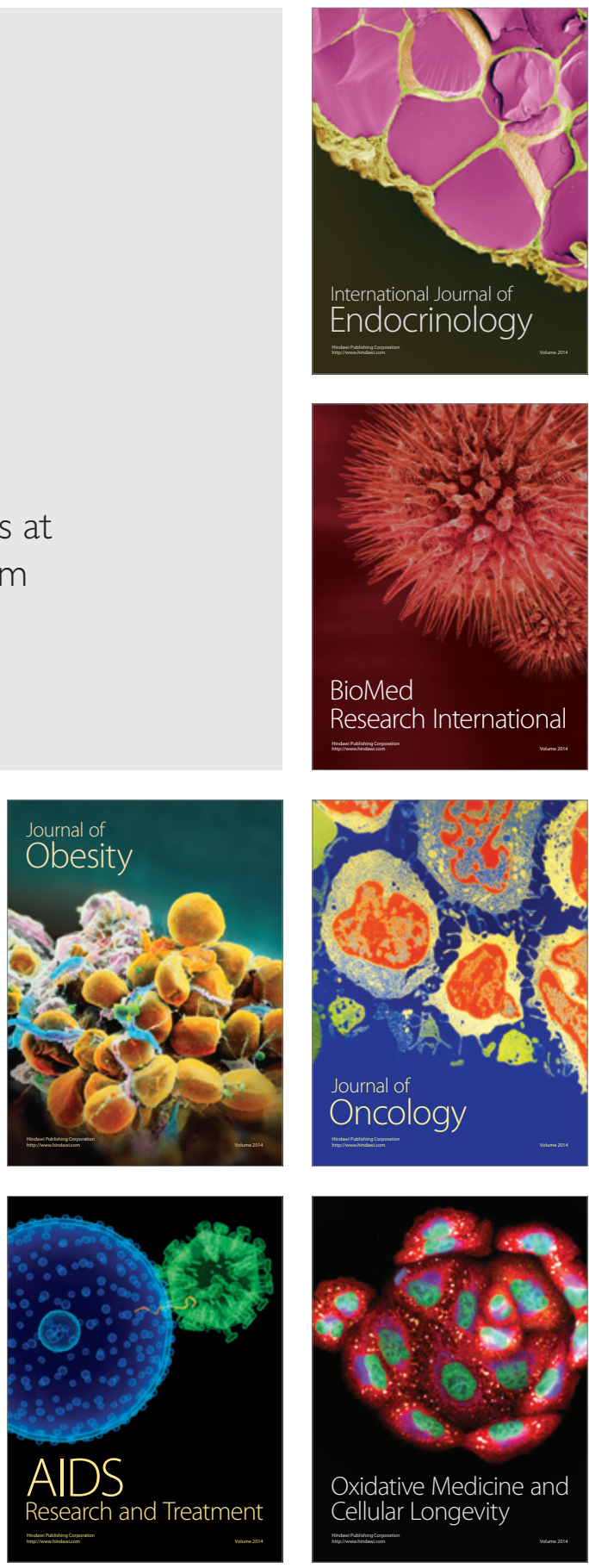